SHORT COMMUNICATION

\title{
Sugar composition of wild fruits in Hong Kong, China
}

\author{
ICE W. P. KO*, RICHARD T. CORLETT* and RUO-JUN XU† \\ *Department of Ecology and Biodiversity, University of Hong Kong, Pokfulam Road, Hong \\ Kong \\ $\dagger$ Department of Zoology, University of Hong Kong, Pokfulam Road, Hong Kong \\ (Accepted 20 December 1997)
}

KEY WORDS: fruit, frugivory, carbohydrates, sugars, birds, mammals.

Soluble carbohydrates are the major nutritional reward in the pulp of most vertebrate-dispersed fruits (Corlett 1996, Herrera 1987, Johnson et al. 1985, Jordano 1995). However, although detailed analyses have been made of the carbohydrate content of many cultivated fruits (e.g. Nagy et al. 1990, Widdowson \& McCance 1935), most studies of wild fruits have only quantified total soluble carbohydrates (e.g. Conklin \& Wrangham 1994, Corlett 1996, Foster \& McDiarmid 1983, Herrera 1987, Izhaki 1992). This is unfortunate because relatively minor differences in the chemical structure of nutrients can have profound implications for frugivorous animals (Martinez del Rio \& Restrepo 1993), and the fruit choices of these animals may, in turn, have major implications for the abundance and distribution of plant species.

Members of the sturnid-muscicapid bird lineage have been found to lack an intestinal sucrase and to avoid sucrose solutions when given a choice (Martinez del Rio et al. 1988, Martinez del Rio 1990, Martinez del Rio \& Restrepo 1993, Schuler 1983). Even birds which possess a sucrase may digest sucrose relatively inefficiently and prefer hexoses in choice tests (Avery et al. 1995, Martinez del Rio et al. 1992). It has been reported that the pulp of most bird-dispersed fruits is rich in glucose and fructose but contains little sucrose, but the data set on which these generalisations were based has not been published (Martinez del Rio et al. 1992). Conversely, taste preference thresholds in primates are consistently lower for sucrose than other food sugars (Laska 1996) and both cultivated fruits, which are presumably derived largely from mammal-dispersed 
ancestors, and wild mammal-dispersed fruits, often contain large amounts of sucrose (Martinez del Rio et al. 1992, Nagy et al. 1990, Widdowson \& McCance 1935).

The aim of this study was to test the validity of these generalisations about fruit sugars, particularly for species eaten by birds, which are the major seed dispersal agents in Hong Kong. This work forms part of a long-term study of the ecology of seed dispersal in Hong Kong, China, where at least 27\% (482 spp) of the total angiosperm flora of $c$. 1800 species has fleshy, presumably vertebrate-dispersed, fruits (Corlett 1996). Fruit production is highly seasonal and both fruit diversity and abundance peak in December/January (Corlett 1993). More than 35 resident bird species and 40 migrant species probably eat at least some fruit but the major avian frugivores are resident species of Garrulax, Pycnonotus, Zosterops and and migrant species of Turdus, Luscinia and Tarsiger (Corlett 1996, 1998). The major mammalian frugivores are two species of fruit bat (Cynopterus sphinx (Vahl) and Rousettus leschenaulti (Desmarest)), two species of civet (Paguma larvata (Hamilton-Smith) and Viverricula indica (Gray)), one primate (Macaca mulatta), and three species of rat (Corlett 1996). Plant names follow Corlett (1996).

Ripe fruits were collected from 58 local plant species, representing as wide a taxonomic and morphological range as practical, and including representatives of all the major bird-dispersed genera in Hong Kong (Table 1). Each fruit sample consisted of pooled collections from at least five individuals of the species. The species selected represent 35 angiosperm families and the gymnosperm, Gnetum montanum, the fleshy seeds of which are the functional equivalent of angiosperm fruits. Information on the dispersal agents for the plant species studied was derived from Corlett (1996), with a few additions as a result of subsequent studies. Mealworms (Tenebrio molitor) and grasshoppers (Tettigoniidae) were used for a comparison between fruit and insect carbohydrate profiles. All samples were frozen as soon as possible after collection and stored at $-18^{\circ} \mathrm{C}$. They were then freeze-dried and the pulp ground up in a mortar. All seeds were removed but the fruit skin was included with the pulp, except in Choerospondias axillaris, Garcinia oblongifolia, Gnetum montanum and Melodinus suaveolens, where the thick skin is removed by frugivores. The ground pulp samples were then oven-dried at $70^{\circ} \mathrm{C}$ until constant weight and kept in a desiccator until analysis.

Sugars were extracted from $0.2 \mathrm{~g}$ of dry sample in boiling deionised water for $2 \mathrm{~min}$ and then cooled in a water bath. Preliminary experiments suggested that this procedure was the best compromise between incomplete extraction of soluble carbohydrates and the increasing risk of sucrose hydrolysis with prolonged boiling (I. W. P. Ko, unpubl. data). The water extract was then homogenised on ice for 5 min before filtering. An aliquot of the filtrate was used for measuring the total soluble carbohydrates by the anthrone assay (Quarmby \& Allen 1989). Another aliquot of the same filtrate was centrifuged 
Table 1. Carbohydrate content of fruit pulp, measured by HPLC and expressed as percentage of dry pulp weight, for 58 Hong Kong plant species. nd = not detectable.

\begin{tabular}{|c|c|c|c|c|c|c|c|}
\hline Family & Fruit species & Glucose & Fructose & $\mathrm{G}: \mathrm{F}$ & Sucrose & $\mathrm{TSC}^{\mathrm{a}}$ & $\begin{array}{c}\text { Dispersal } \\
\text { agent }^{\mathrm{b}}\end{array}$ \\
\hline Anacardiaceae & Choerospondias axillaris & 4.0 & 4.3 & 0.93 & 11.35 & 32.0 & GM \\
\hline \multirow[t]{2}{*}{ Annonaceae } & Desmos chinensis & 11.5 & 14.4 & 0.80 & nd & 42.0 & $\mathrm{~B}$ \\
\hline & Uvaria calamistrata & 6.9 & 15.1 & 0.45 & nd & 42.5 & $\mathrm{~m}$ \\
\hline \multirow[t]{3}{*}{ Apocynaceae } & Alyxia sinensis & 12.2 & 10.3 & 1.19 & 2.76 & 37.7 & $\mathrm{~b}$ \\
\hline & Melodinus sauveolens & 7.9 & 9.2 & 0.87 & 12.24 & 32.1 & M \\
\hline & Rauvolfia verticillata & 25.1 & 18.4 & 1.36 & nd & 63.3 & $\mathrm{~b}$ \\
\hline \multirow[t]{2}{*}{ Aquifoliaceae } & Ilex asprella & 20.1 & 22.1 & 0.91 & nd & 60.3 & B \\
\hline & Ilex pubescens & 13.6 & 15.5 & 0.88 & nd & 37.5 & B \\
\hline Araliaceae & Schefflera octophylla & 5.2 & 5.5 & 0.95 & 4.60 & 38.0 & $\mathrm{BF}$ \\
\hline Chloranthaceae & Sarcandra glabra & 23.3 & 0.0 & - & nd & 29.0 & B \\
\hline Convallariaceae & Liriope spicatus & 8.3 & 23.0 & 0.36 & nd & 48.5 & B \\
\hline \multirow[t]{2}{*}{ Daphniphyllaceae } & Daphniphyllum & & & & & & \\
\hline & glaucescens & 16.2 & 18.9 & 0.86 & nd & 50.0 & B \\
\hline \multirow[t]{2}{*}{ Ebenaceae } & Diospyros morrisiana & 20.9 & 22.6 & 0.93 & nd & 51.0 & $\mathrm{CB}$ \\
\hline & Diospyros vaccinioides & 16.8 & 18.3 & 0.92 & nd & 37.9 & B \\
\hline Ericaceae & Vaccinium bracteatum & 11.0 & 12.2 & 0.90 & nd & 31.0 & B \\
\hline Euphorbiaceae & Macaranga tanarius & 18.2 & 15.0 & 1.22 & nd & 41.6 & B \\
\hline Gnetaceae & Gnetum montanum & 6.6 & 6.2 & 1.06 & 31.44 & 69.6 & CM \\
\hline Guttiferae & Garcinia oblongifolia & 9.1 & 9.3 & 0.98 & 41.13 & 79.3 & $\mathrm{M}$ \\
\hline Hydrangeaceae & Dichroa febrifuga & 15.6 & 20.5 & 0.76 & nd & 47.0 & $\mathrm{~b}$ \\
\hline \multirow[t]{2}{*}{ Lauraceae } & Persea leptophylla & 2.4 & 6.3 & 0.38 & nd & 35.4 & B \\
\hline & Persea longipedunculata ${ }^{\mathrm{c}}$ & 1.6 & 3.2 & 0.49 & nd & 21.5 & B \\
\hline Loganiaceae & Strychnos angustiflora & 23.2 & 22.9 & 1.01 & nd & 71.1 & $\mathrm{c}$ \\
\hline Menispermaceae & Diploclisia glaucescens & 15.4 & 23.6 & 0.66 & nd & 54.7 & ? \\
\hline \multirow[t]{4}{*}{ Moraceae } & Artocarpus hypargyreus & 14.6 & 12.2 & 1.20 & nd & 52.0 & CM \\
\hline & Ficus hispida & 14.2 & 16.2 & 0.87 & 8.66 & 52.8 & $\mathrm{~F}$ \\
\hline & Ficus microcarpa & 15.5 & 13.3 & 1.17 & nd & 37.0 & $\mathrm{BF}$ \\
\hline & Ficus superba & 17.5 & 13.8 & 1.27 & nd & 38.0 & $\mathrm{BFC}$ \\
\hline \multirow[t]{5}{*}{ Myrsinaceae } & Ardisia punctata & 16.7 & 18.7 & 0.89 & nd & 42.0 & $\mathrm{~b}$ \\
\hline & Ardisia quinquegona & 18.8 & 24.2 & 0.78 & nd & 54.0 & $\mathrm{~b}$ \\
\hline & Embelia laeta & 19.3 & 24.2 & 0.80 & nd & 61.0 & $\mathrm{Cb}$ \\
\hline & Embelia ribes & 24.5 & 26.3 & 0.93 & nd & 50.0 & B \\
\hline & Maesa perlarius & 26.9 & 27.2 & 0.99 & nd & 64.0 & B \\
\hline \multirow[t]{2}{*}{ Myrtaceae } & Syzygium buxifolium & 18.9 & 18.4 & 1.02 & nd & 45.5 & $\mathrm{Cb}$ \\
\hline & Syzygium levinei & 21.7 & 24.5 & 0.89 & nd & 52.6 & B \\
\hline \multirow[t]{2}{*}{ Oleaceae } & Ligustrum sinensis & 17.7 & 20.1 & 0.88 & nd & 46.0 & B \\
\hline & Osmanthus marginatus & 12.1 & 13.5 & 0.89 & nd & 30.1 & $\mathrm{~b}$ \\
\hline Phormiaceae & Dianella ensifolia & 20.3 & 25.3 & 0.80 & nd & 47.0 & B \\
\hline \multirow[t]{2}{*}{ Rhamnaceae } & Berchemia racemosa & 20.5 & 21.8 & 0.94 & nd & 53.0 & B \\
\hline & Sageretia theezans & 12.7 & 11.8 & 1.07 & nd & 39.0 & B \\
\hline \multirow[t]{3}{*}{ Rosaceae } & Photinia prunifolia & 17.0 & 7.8 & 2.16 & nd & 20.0 & B \\
\hline & Rhaphiolepis indica & 24.6 & 11.6 & 2.13 & nd & 27.4 & $\mathrm{BC}$ \\
\hline & Rhodomyrtus tomentosa & 16.3 & 18.1 & 0.90 & 5.24 & 54.0 & BCM \\
\hline \multirow[t]{2}{*}{ Rubiaceae } & Psychotria rubra & 24.6 & 22.8 & 1.08 & nd & 62.0 & B \\
\hline & Psychotria serpens & 26.8 & 16.4 & 1.64 & nd & 52.4 & B \\
\hline \multirow[t]{2}{*}{ Rutaceae } & Acronychia pedunculata & 9.7 & 14.3 & 0.67 & 32.64 & 77.0 & BCf \\
\hline & Atalantia buxifolia & 15.4 & 26.0 & 0.59 & nd & 54.7 & $\mathrm{~b}$ \\
\hline Santalaceae & Dendrotrophe frutescens & 12.2 & 16.1 & 0.76 & nd & 36.0 & $\mathrm{Cb}$ \\
\hline Simarubaceae & Brucea javanica & 4.7 & 5.4 & 0.86 & nd & 12.8 & $\mathrm{~b}$ \\
\hline Smilacaceae & Smilax china & 17.9 & 17.4 & 1.03 & nd & 47.7 & B \\
\hline Symplocaceae & Symplocos lucida & 13.0 & 8.2 & 1.59 & nd & 24.5 & $\mathrm{~b}$ \\
\hline Theaceae & Adinandra millettii & 20.5 & 19.1 & 1.08 & nd & 57.2 & $\mathrm{~b}$ \\
\hline \multirow[t]{2}{*}{ Thymelaeaceae } & Wikstroemia indica & 22.6 & 23.1 & 0.98 & 4.96 & 62.0 & B \\
\hline & Wikstroemia nutans & 23.0 & 25.0 & 0.92 & nd & 63.0 & $\mathrm{~b}$ \\
\hline Ulmaceae & Celtis sinensis & 13.7 & 17.2 & 0.80 & nd & 38.0 & B \\
\hline Verbenaceae & Callicarpa kochiana & 23.9 & 32.6 & 0.73 & nd & 74.0 & B \\
\hline & Lantana camara & 14.3 & 17.9 & 0.80 & nd & 44.0 & B \\
\hline Vitaceae & Columella corniculata & 10.6 & 18.4 & 0.58 & nd & 43.0 & $\mathrm{~b}$ \\
\hline Zingiberaceae & Alpinia chinensis & 8.5 & 8.3 & 1.02 & 10.12 & 34.0 & $\mathrm{~b}$ \\
\hline
\end{tabular}

${ }^{a} \mathrm{TSC}=$ total soluble carbohydrates by the anthrone method.

${ }^{\mathrm{b}}$ Dispersal agent, from (Corlett 1996), with additions and corrections: upper case $=$ observed, lower case $=$ inferred, $\mathrm{B}, \mathrm{b}=$ bird, $\mathrm{C}, \mathrm{c}=$ civet $, \mathrm{F}, \mathrm{f}=$ fruit bat, $\mathrm{M}, \mathrm{m}=$ macaque.

${ }^{c}$ Persea longipedunculata (S. Lee \& F. N. Wei) Kosterm. was misidentified as Machilus thunbergii in Corlett (1993, 1996). 
at $10,000 \mathrm{rpm}$ for $5 \mathrm{~min}$ and filtered again with $0.45 \mu \mathrm{m}$ filters (Millipore) before injecting into a high-performance liquid chromatograph (HPLC), equipped with an aminopropyl bonded phase column (Supercosil LC- $\mathrm{NH}_{2}$ ) and refractive index detector (Shimadzu). The solvent was acetonitrile:water (83:17) at a flow rate of $1.5 \mathrm{ml} \mathrm{min} \mathrm{m}^{-1}$ at room temperature. The HPLC was connected to an integrator (Hewlett-Packard) and peak heights were used to quantify sugar amounts against standards in two replicates for each species.

The effective detection limit with the HPLG used in this study is $c .1 \%$ of pulp dry weight for glucose and fructose and $2.5 \%$ of pulp dry weight for sucrose. No sugars were detected in the insects and only glucose, fructose and sucrose in the fruits (Table 1). All fruits contained glucose (median 15.9\%, range 1.6-26.9\% of pulp dry weight) and all except Sarcandra glabra contained fructose (median 17.3, 0.0-32.6\%). The glucose : fructose ratio, excluding Sarcandra, ranged from 0.36-2.16, with a median of 0.91 . Only 11 fruit species contained detectable sucrose (median 10.1, 2.8-41.1\%) and in only six of these was it the predominant sugar.

The total sugar content as determined by HPLG (glucose + fructose + sucrose: median 35.4, 4.8-59.5\%) was almost always lower than that determined by the anthrone method (46.5, 12.8-79.3\%). Although it is possible that this reflects the presence of sugars which could not be detected by the HPLC set-up used here, this is unlikely. Extracts from four fruit species, including some with the widest divergence between HPLC and anthrone results, were analysed independently with a different column, solvent, detector and standards but no additional sugars were detected (L. Ramsden, pers. comm.). More likely, the relatively high anthrone results reflect the lower specificity of this test to soluble carbohydrates (Morris 1948). The sugar contents determined by the anthrone method in this study were also usually lower than those given in Corlett (1996) for the same species (56.0, 19.0-87.0\%). This can be explained by the much more rigorous extraction method used in the latter study: $2 \mathrm{~h}$ of boiling in contrast to the $2 \mathrm{~min}$ used here. Preliminary experiments showed that this prolonged boiling tended to result in the hydrolysis of sucrose to hexoses in some fruit species, so it is unsuitable for detailed sugar analysis.

Birds are known to consume 29 of the fruit species without detectable sucrose but only four fruit species with detectable sucrose, viz. Acronychia pedunculata, Rhodomyrtus tomentosa, Schefflera octophylla and Wikstroemia indica. The first three of these are also consumed by mammals, although only occasionally in the case of Scheffera. Of these species, only in Acronychia is sucrose the predominant sugar. The only birds we have observed feeding on this fruit species are bulbuls, (Pycnonotus spp.), which have an intestinal sucrase (I. W. P. Ko, unpubl. data). Rhodomyrtus and Schefflera, with 4-6\% sucrose, are consumed by many bird species, including members of the Muscicapidae and Sturnidae which lack a sucrase. Two other fruit species with detectable sucrose, Alpinia chinensis and 
Alyxia sinensis, are probably consumed by birds (Corlett 1996). Mammals (civets, fruit bats and/or the rhesus macaque) are known to consume eight fruit species containing sucrose, including five in which sucrose is the major sugar. Mammals (civets and/or fruit bats) also eat at least eight species with no detectable sucrose, all but one (Artocarpus) of which are known or suspected to also be eaten by birds. Judging by their size, the fruits of Uvaria calamistrata, which also contain no sucrose, are eaten only by mammals.

This study has confirmed that glucose and fructose are the major soluble sugars in fruit pulp, particularly in species dispersed by birds. This is true across a wide range of families, in which the fruit pulp has a variety of origins. However, although frugivorous birds in Hong Kong consume mostly hexosedominated fruits, this is not evidence for sucrose avoidance since most sucroserich fruits in the sample were unavailable to birds because of their size or thick peel. Indeed, the one accessible, sucrose-dominated fruit for which there are feeding records, Acronychia pedunculata, is eaten by birds. The study also confirms that mammals will eat sucrose-rich fruits, although they eat as many hexose-dominated species in our sample.

Martinez del Rio et al. (1992) hypothesised that the low sucrose/hexose ratios in the pulp of bird-dispersed fruits are the result of the need for birds to rapidly dispose of seeds, which decrease gut capacity and increase weight. The resulting fast gut passage rates may not provide enough time for the complete hydrolysis of sucrose. They further suggested that the lack of intestinal sucrase in the sturnid-muscicapid clade originated in an insectivorous common ancestor and the subsequent development of frugivory in many members of this lineage was permitted by the already existing hexose dominance in fruit pulps.

Seed loads are less critical in most mammals, so passage times can be longer and sucrose can presumably be completely assimilated. A larger sample of mammal-dispersed fruits would be needed to detect differences between mammal taxa, but it is noticeable that the two 'primate fruits' in our sample, Garcinia and Melodinus, which have a rind which must be removed before the fruit pulp is ingested, are both sucrose-dominated, while only one fruit eaten by fruit bats, Ficus hispida, contains detectable sucrose. All primates tested show a lower taste preference threshold for sucrose (Laska 1996) while fruit bats have gut passage times as fast as frugivorous birds (Phua \& Corlett 1989) and might be expected to prefer hexoses. More work is needed on the pulp sugars of mammal fruits and the sugar preferences of frugivorous mammals other than primates.

In contrast to phylogenetic conservatism of sucrose metabolism in birds, hexose- and sucrose-dominated fruit pulps may occur within the same plant genus (Lim 1996), suggesting that this character may respond quickly to natural selection. Carbon fixed by fruit photosynthesis makes a relatively small contribution to the total carbon budget of most fruits so most carbon must be 
imported. The main transported photosynthate in most plants is sucrose and the approximately equal proportion of glucose and fructose in most fruits presumably results from the hydrolytic cleavage of this sucrose in the fruit. Deviations from the expected 1: 1 ratio may reflect the existence of other transport molecules and/or the differential use of sugars in fruit metabolism. The unusual, glucose-only pulp of Sarcandra glabra would merit further investigation.

\section{ACKNOWLEDGEMENTS}

We are grateful to Laura Wong, Victor Yeung, Lawrence Ramsden and Y. L. Chan for technical assistance and advice.

\section{LITERATURE GITED}

AVERY, M. L., DEGKER, D. G., HUMPHREY, J. S., HAYES, A. A. \& LAUKERT, C. G. 1995. Colour, size and location of artificial fruits affect sucrose avoidance by cedar waxwings and European starling. Auk 112:436-444.

CONKLIN, N. L. \& WRANGHAM, R. W. 1994. The value of figs to a hind-gut fermenting frugivore: a nutritional analysis. Biochemical Systematics and Ecology 22:137-151.

CORLETT, R. T. 1993. Reproductive phenology of Hong Kong shrubland. Journal of Tropical Ecology 9:501-510.

CORLETT, R. T. 1996. Characteristics of vertebrate-dispersed fruits in Hong Kong. Journal of Tropical Ecology 12:819-833.

CORLETT, R. T. 1998. Frugivory and seed dispersal by birds in Hong Kong shrubland. Forktail 13: in press.

FOSTER, M. S. \& McDIARMID, R. W. 1983. Nutritional value of the aril of Trichilia cuneata, a bird-dispersed fruit. Biotropica 15:26-31.

HERRERA, C. M. 1987. Vertebrate-dispersed plants of the Iberian Peninsula: a study of fruit characteristics. Ecological Monographs 57:305-331.

IZHAKI, I. 1992. A comparative analysis of the nutritional quality of mixed and exclusive fruit diets for yellow-vented bulbuls. Condor 94:912-923.

JOHNSON, R. A., WILLSON, M. F. \& THOMPSON, J. N. 1985. Nutritional values of wild fruits and consumption by migrant frugivorous birds. Ecology 66:819-827.

JORDANO, P. 1995. Angiosperm fleshy fruits and seed dispersers: a comparative analysis of adaptation and constraints in plant-animal interactions. American Naturalist 145:163-191.

LASKA, M. 1996. Taste preference thresholds for food-associated sugars in the squirrel monkey (Saimiri sciureus). Primates 37:91-95.

LIM, G. 1996. Tomato. Pp. 709-728 in Zamski E. \& Schaffer A. A. (eds). Photoassimilate distribution in plants and crops. Marcel Dekker, New York.

MARTINEZ del RIO, C. 1990. Dietary, phylogenetic and ecological correlates of the intestinal sucrase and maltase activity in birds. Physiological Zoology 63:987-1011.

MARTINEZ del RIO, C., BAKER, H. G. \& BAKER, I. 1992. Ecological and evolutionary implications of digestive processes: bird preferences and the sugar constituents of floral nectar and fruit pulp. Experientia 48:544-551.

MARTINEZ del RIO, C. \& RESTREPO, C. 1993. Ecological and behavioral consequences of digestion in frugivorous animals. Vegetatio 107/108:205-216.

MARTINEZ del RIO, G., STEVENS, B. R., DANEKE, D. E. \& ANDREADIS, P. T. 1988. Physiological correlates of preference and aversion for sugars in three species of birds. Physiological Zoology 61:222229.

MORRIS, D. L. 1948. Quantitative determination of carbohydrates with Dreywood's anthrone reagent. Science 107:254-255.

NAGY, S., SHAW, P. E. \& WARDOWSKI, W. F. 1990. Fruits of tropical and subtropical origin: composition, properties and uses. Florida Science Source, Florida.

PHUA, P. B. \& CORLETT, R. T. 1989. Seed dispersal by the lesser short-nosed fruit bat (Cynopterus brachyotis, Pteropodidae, Megachiroptera). Malayan Nature Journal 42:251-256.

QUARMBY, C. \& ALLEN, S. E. 1989. Organic Constituents, Pp. 160-200 in Allen S.E. (ed.). Chemical analysis of ecological materials. (2nd edition). Blackwell Scientific Publications, London. 
SCHULER, W. 1983. Responses to sugars and their behavioral mechanisms in the starling (Sturnus vulgaris). Behavioral Ecology and Sociobiology 13:243-251.

WIDDOWSON, E. M. \& McCANCE, R. A. 1935. The available carbohydrate of fruits: determination of glucose, fructose, sucrose and starch. Biochemical Journal 29:151-156. 